BACKGROUND: In contrast to cellular receptors, soluble receptors do not enhance the cellular activation because they do not have transmembranic and cytoplasmic parts, acting thereby as endogenous regulatory mechanisms against systemic functions of cytokines.

Aim: To measure serum concentrations of the soluble interleukin-2 receptor (sIL2R), soluble interleukin-4 receptor (sIL4R), soluble interleukin-6 receptor (SIL6R), and soluble tumor necrosis factor- $\alpha$ receptor I and soluble tumor necrosis factor- $\alpha$ receptor II, during the perinatal and early neonatal period, in order to evaluate their role in activation of immune response in labor and the first days postpartum.

Methods: Soluble receptor serum concentrations were determined by enzyme-linked immunosorbent assay, in 45 healthy, full-termed neonates during the first and fifth days after birth, in 25 of their mothers (MS), in 25 samples of umbilical cords (UC) and in 25 healthy adult donors age-matched with the mothers (controls).

Results: Soluble receptor serum concentrations showed considerable changes during labor and early neonatal life, being significantly higher both in MS (except sIL6R) and in neonatal sample UC, first and fifth days after birth, compared with controls $(p<$ $0.0001)$. Neonatal serum SIL2R and SIL6R increased significantly from birth to the fifth day, while the remaining receptors showed a rapid increase in the first day $(p<0.0001)$, declining significantly thereafter $(p<0.0001)$.

Conclusion: Our findings suggest that the elevated concentrations of all studied soluble cytokine receptors reflect the activation of immune response, and represent also regulatory protective mechanisms for mother and fetus-neonate against the systemic function of cytokines during labor and early neonatal life.

Key words: Soluble interleukin-2 receptor, Soluble interleukin-4 receptor, Soluble interleukin-6 receptor, Soluble tumor necrosis factor- $\alpha$ receptor I, Soluble tumor necrosis factor- $\alpha$ receptor II, Neonates

\section{Cytokine soluble receptors in perinatal and early neonatal life}

\author{
Efthimia Protonotariou ${ }^{1}$, Demetrios Rizos ${ }^{1}$, \\ Ariadne Malamitsi-Puchner ${ }^{2}$, Evangelia Moira ${ }^{1}$, \\ Angeliki Sarandakou ${ }^{1, \mathrm{CA}}$ and \\ Emmanuil Salamalekis ${ }^{3}$
}

${ }^{1}$ Hormone Laboratory, ${ }^{2}$ Neonatal Unit and ${ }^{3} 2 \mathrm{nd}$ Department of Obstetrics and Gynecology, University of Athens, 'Aretaieion' Hospital, 76, Vas. Sophias Ave, Athens, Greece

\author{
${ }^{\mathrm{CA}}$ Corresponding author \\ Home address: Ivis 101, Paleon Phaleron, 17561, \\ Greece \\ E-mail: dsaran@tee.gr
}

\section{Introduction}

Cytokines, like hormones, interact with specific cellular receptors on the surface of target cells. Cytokine receptors show high affinity with the target molecules, and thus a small amount of cytokine is adequate for the biological product.

In contrast to the membranic receptors, soluble receptors do not enhance the cellular activation because they do not have transmembranic and cytoplasmic parts. For that reason they act as endogenous regulatory mechanisms against the systemic (mainly) function of cytokines. ${ }^{1}$

Two types of such inhibitors or regulatory mechanisms have been recognized:
- the soluble receptors (type II inhibitors) that compete with the membranic ones for cytokine binding, which is a general phenomenon; and

- the antagonists of receptors (type I inhibitors) that are structurally homologous with cytokines and, in coupling with the receptors, cannot transduce signals, and thus they compete with cytokine's actions (e.g. interleukin-1 antagonist).

Type II inhibitors are thought to act as stabilizers, eliminating the systemic (harmful) activities of cytokines, and amplifying their paracrine (beneficial) activities. $^{2,3}$ 
Our study aimed to determine soluble interleukin2 receptor (sIL2R), soluble interleukin-4 receptor (sIL4R), soluble interleukin-6 receptor (sIL6R) and soluble tumor necrosis factor- $\alpha$ receptor I (sTNFRI) and soluble tumor necrosis factor- $\alpha$ receptor II (sTNFRII) during the perinatal and early neonatal period, in order to evaluate their role in activation of immune response in labor and the first days postpartum.

\section{Materials and methods}

The Ethics Committee of our Teaching Hospital approved the study and written informed consent was acquired from the participating mothers and controls with admission in the clinic. This study comprised 45 healthy full-term, appropriate for gestational age, neonates, born after a single uncomplicated pregnancy and delivery from healthy, nonsmoking mothers (age, mean \pm standard deviation $23.5 \pm 4.2$ years, range 20-40 years). Apgar scores were in all cases $\geq 8$ in the first and fifth minute, and placentas were normal in appearance and weight (mean weight $446 \pm 13 \mathrm{~g}$ ). Demographic data of participating neonates are presented in Table 1.

In the study, the 25 mothers of the neonates also participated, as well as 25 healthy, non-pregnant, non-smoking women aged $24.0 \pm 4.0$ years (range 21-39 years) with regular menstrual cycles, all in periovulation, who served as controls.

Blood was drawn from controls, from mothers (MS), before delivery (first stage of labor), from the doubly clamped umbilical cord (UC) at delivery (mixed arteriovenous blood), and form the neonates in the first $(1 \mathrm{~N})$ and fifth $(5 \mathrm{~N})$ days postpartum. Blood was collected in pyrogen-free tubes and was immediately centrifuged after clotting; the supernatant serum was kept frozen at $-30^{\circ} \mathrm{C}$ until assayed.

All cytokine soluble receptors were determined by enzyme immunoassay and enzyme-linked immunosorbent assay, using commercially available Kits. Sensitivities, inter-assay and intra-assay coefficients of variation were, respectively: $50 \mathrm{pg} / \mathrm{ml}, 7.5 \%$ and $5.2 \%$ for sIL2R (Cellfree ${ }^{\circledR}$ sIL-2R; T Cell Sciences, Cambridge, MA, USA); $5 \mathrm{pg} / \mathrm{ml}, 5.2 \%$ and $2.6 \%$ for sIL4R (Quantikine ${ }^{\circledR}$ hIL-4sR; R\&D Systems, MN,

Table 1. Demographic characteristics of neonates

\begin{tabular}{ll}
\hline Sex & \\
Girls & $n=23$ \\
Boys & $n=22$ \\
Birthweight [mean (range)] & $3352 \mathrm{~g}(2580-3950 \mathrm{~g})$ \\
Weeks of pregnancy [mean (range)] & $39.4(38-41)$ \\
Mode of delivery & \\
$\quad$ Elective caesarean section & $n=11$ \\
Vaginal delivery & $n=34$ \\
Apgar scores & $8-10$ \\
\hline
\end{tabular}

USA); $250 \mathrm{pg} / \mathrm{ml}, \quad 4.2 \%$ and $2.6 \%$ for sIL6R (Quantikine ${ }^{\circledR}$ hIL-6sR; R\&D Systems, MN, USA); 30 $\mathrm{pg} / \mathrm{ml}, 3 \%$ and $2.9 \%$ for sTNFRI (Quantikine ${ }^{\circledR}$ sTNF RI; R\&D Systems, MN, USA); and $10 \mathrm{pg} / \mathrm{ml}, 3.5 \%$ and $2.5 \%$ for sTNFRII (Quantikine ${ }^{\circledR}$ STNF RII; R\&D Systems).

Statistical analysis involved non-parametric tests for sIL4R [Wilcoxon test, Spearman correlation coefficient and Kruskal-Wallis analysis of variance (ANOVA)] and parametric tests ( $t$-test, Pearson's correlation coefficient, one-way ANOVA) for the remaining receptors, since data presented abnormal and normal distributions, respectively (KolmogorovSmirnov test). The level $p<0.05$ was considered statistically significant.

\section{Results}

The summarized data are presented in Table 2 .

Serum sIL2R concentrations in all four samples MS, $\mathrm{UC}, 1 \mathrm{~N}$ and $5 \mathrm{~N}$ were significantly higher than those in controls $(p<0.0001)$, showing an increased tendency in neonatal samples from UC to the $5 \mathrm{~N}(p<$ 0.0001).

Both $1 \mathrm{~N}$ and $5 \mathrm{~N}$ sIL2R concentrations were considerably higher in neonates born vaginally $(838.2 \pm$ $204.6 \mathrm{U} / \mathrm{ml}$ and $1662 \pm 517.8 \mathrm{U} / \mathrm{ml}$, respectively), than in those delivered by elective caesarean section $(591.3 \pm 225.2 \mathrm{U} / \mathrm{ml}$ and $1165.3 \pm 495.4 \mathrm{U} / \mathrm{ml} ; p<$ $0.01)$.

Serum sIL4R concentrations were markedly elevated in MS, compared with those in controls $(p<$ $0.0001)$, in UC $(p<0.0005)$, in $1 \mathrm{~N}(p<0.03)$ and in $5 \mathrm{~N}(p<0.0001)$. MS concentrations were dependent significantly on the mode of delivery, being higher in cases of vaginal delivery (median $148 \mathrm{pg} / \mathrm{ml}$, range 95-398 pg/ml) compared with those of elective caesarean section (median $119.3 \mathrm{pg} / \mathrm{ml}$, range 59$235 \mathrm{pg} / \mathrm{ml} ; p<0.05)$.

Serum sIL4R concentrations were significantly elevated in all three neonatal samples, compared with those in controls $(p<0.0001)$, followed by a marked increase in $1 \mathrm{~N}(p<0.01)$ and decreased also significantly in $5 \mathrm{~N}(p<0.01)$.

A strong negative correlation was found between sIL4R and interleukin-4 (IL-4) concentrations in both neonatal samples $1 \mathrm{~N}(r=-0.48, p<0.002)$ and $5 \mathrm{~N}$ $(r=-0.45, p<0.0065)$.

Serum sIL6R values in neonatal samples showed a significant continuous increase from UC to the $5 \mathrm{~N}$ samples $(p<0.002)$.

Serum sIL6R values in $1 \mathrm{~N}$ and $5 \mathrm{~N}$ were significantly higher than in MS $(p<0.01$ and $p<0.0001$, respectively) and controls ( $p<0.01$ and $p<0.0002$ respectively), while no significant difference was found among UC, MS and controls. 
Table 2. Soluble receptor concentrations in maternal serum (MS), umbilical cord (UC), neonatal serum day 1 (1N) and neonatal serum day $5(5 \mathrm{~N})$, and in adult controls

\begin{tabular}{|c|c|c|c|c|c|}
\hline Samples & $\operatorname{sIL2R}(\mathrm{U} / \mathrm{ml})$ & sIL4R (pg/ml) & sIL6R (pg/ml) & STNFRI (pg/ml) & sTNFRI $(\mathrm{pg} / \mathrm{ml})$ \\
\hline $\mathrm{MS}(n=25)$ & $682 \pm 318$ & $132.5(59-398)$ & $26096 \pm 8489$ & $1320 \pm 418$ & $1939 \pm 605$ \\
\hline UC $(n=25)$ & $695 \pm 205$ & $75.5(39.5-12)$ & $32345 \pm 9043$ & $2050 \pm 708$ & $3124 \pm 792$ \\
\hline $1 \mathrm{~N}(n=45)$ & $785 \pm 318$ & $100.0(48-312)$ & $36635 \pm 10379$ & $3366 \pm 950$ & $4241 \pm 957$ \\
\hline $5 \mathrm{~N}(n=45)$ & $1560 \pm 638$ & $74.0(30-218)$ & $43650 \pm 10119$ & $2155 \pm 613$ & $3567 \pm 784$ \\
\hline Adult controls $(n=45)$ & $487 \pm 163$ & $38.5(20-88)$ & $24926 \pm 9682$ & $933 \pm 315$ & $1344 \pm 290$ \\
\hline
\end{tabular}

Data presented as mean \pm standard deviation, or as mean (range).

A strong correlation was found between sIL6R concentrations in UC and $1 \mathrm{~N}(r=0.85, p<0.002)$ and between $1 \mathrm{~N}$ and $5 \mathrm{~N}(r=0.8, p<0.0001)$.

Serum sTNFRI and sTNFRII values showed an intense increase from UC to $1 \mathrm{~N}(p<0.0001$ and $p<0.001$, respectively), decreasing significantly thereafter from $1 \mathrm{~N}$ to $5 \mathrm{~N}(p<0.0001$ and $p<0.01$, respectively).

Serum sTNFRI and sTNFRII concentrations in MS were significantly higher compared with those in controls ( $p<0.0005$ and $p<0.02$, respectively).

Moreover, a strong correlation was found among sTNFRI concentrations in MS and $1 \mathrm{~N}$ samples $(r=$ $0.4, p<0.01$ ), and among sTNFRII between $1 \mathrm{~N}$ and $5 \mathrm{~N}$ samples $(r=0.7, p<0.0002)$.

\section{Discussion}

The development of immunity in neonates may be visualized as a series of adaptive cellular responses to an ever-changing and potentially hostile environment. So, the significant elevation of neonatal sIL2R concentrations, in this study, may be attributed to the response of the newborn immune system to a changing internal and external environment.

Age-related changes in serum sIL2R concentrations in healthy persons have already been documented, and the highest values are recorded during infancy. ${ }^{4}$ In agreement with these findings, we have previously reported postnatal changes in serum sIL2R concentrations. $^{5}$

Moreover, the dependence of sIL2R on the mode of delivery indicates that term parturition is strongly connected with a stimulation of cytokine network, 6,7 which is directly reflected in the high receptor neonatal values of the first and fifth days after birth.

The exact function of sIL2R is still undefined. It is suggested that it should be an immunoregulatory molecule, acting competitively with the membranic receptor for binding with IL-2, and therefore suppresses the systemic or local immune reactions. ${ }^{8}$ In accordance with this immunosuppressive activity, high amounts of this molecule were found in many pathological conditions, which are related to inflammation ${ }^{9,10}$ and cancer. ${ }^{11-13}$ High concentrations of sIL2R have also been recorded in transplant recipi- ents while an exponential further increase is rated as an early and reliable marker of graft rejection. ${ }^{14}$

Concentrations of sIL4R were high in maternal serum as well as in all three neonatal samples, the highest being found in the first day after birth. Our findings are consistent with a previous study of sIL4R in infants, where the highest values were found in healthy children in comparison with others suffering from asthma or acute respiratory infection. ${ }^{15}$

SIL4R is also found under normal conditions as well as in allergic inflammation. ${ }^{15}$ Its high concentrations in maternal serum corroborate its production by placenta and adjacent feto-maternal tissue. ${ }^{16}$ Because of its dependence on the mode of delivery, it amplifies the beneficial influence of vaginal delivery in the activation of the immune system.

The rise of sIL4R concentrations in neonatal serum in the first day after birth reflects an endogenous regulation of IL- 4 activity, which is supported by the strong negative correlation calculated between IL-4 and its receptor in neonatal samples of the first and fifth days postpartum. Recently, there has been great interest in using sIL4R for the safe and effective therapy of asthma, without the use of corticosteroids. $^{1}$

An impressive finding of our study is the concurrent elevation in the three soluble receptors sIL6R, sTNFRI and sTNFRII in maternal serum and neonatal samples. In particular, a markedly continuous increase of sIL6R during the early neonatal life, as with sIL2R, was found, while a rapid elevation of sTNFRI and sTNFRII concentrations in the first day after birth, followed by a decline in the fifth day was estimated.

A possible explanation for this significant elevation of all three soluble receptors during the perinatal period might be due to their regulatory effect against the inflammatory cytokine activity. It is well known that inflammatory cytokines, produced during inflammatory and other immune processes, might cause systemic or local toxic reactions. Considering that, their biosynthesis and release are closely controlled, and with negative feedback mechanisms their activities are narrowed. ${ }^{3}$

Soluble receptors, as was mentioned earlier, belong to the type II inhibitors, which compete with the membranic ones for cytokine binding. They act as protective mechanisms, against the systemic and potentially harmful activities of cytokines, allowing 
their local expression and amplifying their paracrine (beneficial) actions ${ }^{2,3}$.

Soluble sIL6R, like interleukin-6, has been histochemically detected in placental trophoblast ${ }^{17}$ in the developing fetus, especially in fetal adrenal glands, possibly contributing to its development. ${ }^{18}$

Normal pregnancy is associated with increased shedding of TNF- $\alpha$ receptors, particularly of $\mathrm{p} 55$, which has been determined in the maternal as well as in the fetal system. ${ }^{19}$ Soluble p55 has also been discovered in fetal circulation while both $\mathrm{p} 55$ and $\mathrm{p} 75$ have been considered as physiologic constituents of term cord blood in normal pregnancies. ${ }^{20}$ In agreement with these previous reports, p55 values, as well as p75 values in this study, rise significantly in maternal serum during labor, reflecting a respective elevation of their production and implication in the process of delivery.

In contrast to the present findings, elevated p 55 concentrations have been previously found in preeclamptic pregnancies before initiation of labor, compared with normal pregnancy. ${ }^{21}$

Moreover, because the half-life of the receptors are longer than those of TNF- $\alpha$, it has been suggested that both receptors are reliable markers of the cytokine and immune response activation for a long period after the normalization of TNF- $\alpha$ concentrations. ${ }^{22}$

Our findings support the conclusion that high serum soluble receptor concentrations during the perinatal and neonatal periods reflect the activation of immune response, and also represent regulatory protective mechanisms for the mother and fetusneonate against the systemic function of cytokines, during labor and early neonatal life.

\section{References}

1. Steinke JW, Borish L. Th2 cytokines and asthma. Interleukin-4: its role in the pathogenensis of asthma, and targeting it for asthma treatment with interleukin-4 receptor antagonists. Respir Res 2001; 2: 66-70.

2. Gehr G, Braun T, Lesslauer W. Cytokines, receptors and inhibitors. Clin Invest 1992; 70: 64-69.
3. Austgulen R, Liabakk NB, Espevik T. Secretion of soluble receptors for tumor necrosis factor. An immunologic buffer mechanism during normal pregnancy? Tidsskr Nor Laegeforen 1992; 112: 3545-3547.

4. Rubin LA, Nelson DL. The soluble interleukin-2 receptor: biology, function, and clinical application. Ann Intern Med 1990; 113: 619-627.

5. Sarandakou A, Phocas I, Giannaki G, Rizos D, Davri Y, Zourlas PA Immunomarkers in newborn infants. In: Cosmi EV, Di Renzo GC, eds Proceedings of the 2nd World Congress of Perinatal Medicine, Monduzzi Editore, Bologna. 1993: 307-310.

6. MacDonald PC, Koga S, Casey ML. Decidual activation in parturition: examination of amniotic fluid for mediators of the inflammatory response. Ann NY Acad Sci 1991; 622: 315-330.

7. Mitchell MD, Trautman MS, Dudley DJ. Cytokine networking in the placenta. Placenta 1993; 14: 249-275.

8. Zola H, Ridings J, Elliott $\mathrm{S}$, et al . Interleukin-2 receptor regulation and IL2 function in the human infant. Hum Immunol 1998; 59: 615-624.

9. Mahida YR, Gallagher A, Kurlak L, Hawkey CJ. Plasma and tissue interleukin-2 receptor levels in inflammatory bowel disease. Clin Exp Immunol 1990; 82: 75-80.

10. Sarandakou A, Rizos D, Poulakis N, Phocas I. Immunomarkers in pleural effusions. Clin Chem Enzym Commun 1994; 6: 269-275.

11. Steis RG, Macron L, Clark J, Urba W, Long DL, Nelson DL, Maluish AE. Serum soluble IL-2 receptor as a tumor marker in patients with hairy cell leukemia. Blood 1988; 71: 1304-1309.

12. Poulakis N, Sarandakou A, Rizos D, Phocas I, Kontozoglou T, Polyzogopoulos D. Soluble interleukin-2 receptors and other markers in primary lung cancer. Cancer 1991; 68: 1045-1049.

13. Sarandakou A, Phocas I, Sikiotis K, et al. Cytokines in gynecological cancer. Anticancer Res 1997; 17: 3835-3839.

14. Sarandakou A, Agroyannis B, Rizos D, Kapetanaki A, Founda P, Phocas I, Koutsikos D. Soluble interleukin-2 receptors (sIL-2R) and b2-Microglobulin (b2-M) serum levels in renal transplant recipients (RTR). Dialysis Transplant 1993; 22: 246-250.

15. Schauer U, Schmitt M, Muller S, et al. Soluble interleukin-4 receptor in atopic children. Int Arch Allergy Immunol 1995; 108: 175-182.

16. de Moraes-Pinto MI, Vince GS, Flanagan BF, Hart CA, Johnson PM. Localization of IL-4 and IL-4 receptors in the human term placenta, decidua, and amniochorionic membranes. Immunology 1997; 90: $87-$ 94.

17. Jokhi PP, King A, Loke YW. Cytokine production and cytokine receptor expression by cells of the human first trimester placental-uterine interface. Cytokine 1997; 9: 126-137.

18. Dame JB, Juul SE. The distribution of receptors for the proinflammatory cytokines interleukin (IL)- 6 and IL-8 in the developing human fetus. Earl Hum Dev 2000; 58: 25-39.

19. Austgulen R, Liabakk NB, Lien E, Espevik T. Increased levels of soluble tumor necrosis factor-alpha receptors in serum from pregnant women and in serum and urine samples from newborns. Pediatr Res 1992; 33: $82-87$.

20. Hata T, Kawamura T, Fujiwaki R, Aoki S, Hata K, Inada K. Interleukin-4, interleukin-10, and soluble tumor necrosis factor receptors in cord blood. Gynecol Obstet Invest 1997; 43: 155-157.

21. Opsiøn SL, Novick D, Wathen NC, Cope AP, Wallach D, Aderka D. Soluble tumor necrosis factor receptors and soluble interleukin-6 receptor in fetal and maternal sera, coelomic and amniotic fluids in normal and pre-eclamptic pregnancies. J Reprod Immunol 1995; 29: $119-134$.

22. Kupferminc MJ, Peaceman AM, Aderka D, Wallach D, Socol ML. Soluble tumor necrosis factor receptors and interleukin-6 levels in patients with severe preeclampsia. Obstet Gynecol 1996; 88: 420-427.

\section{Received 18 February 2003}

Accepted 10 April 2003 


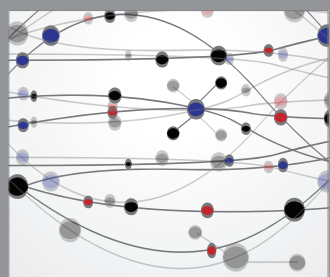

The Scientific World Journal
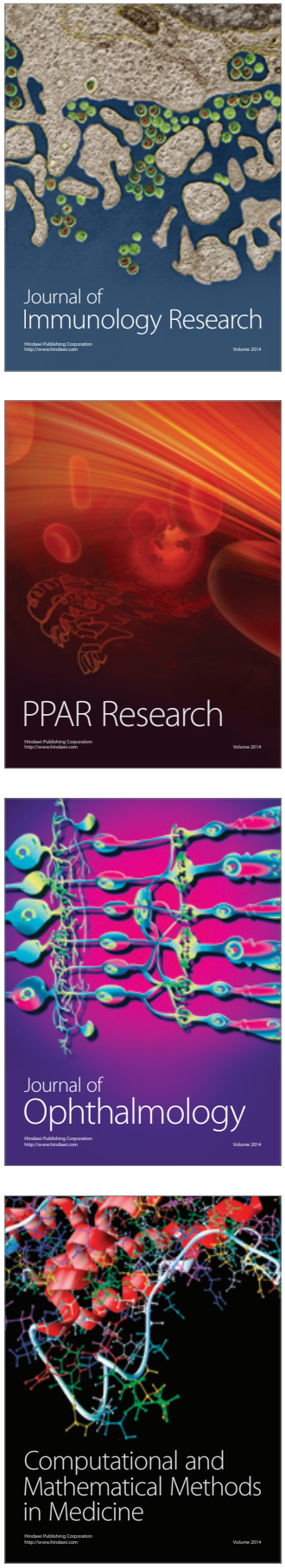

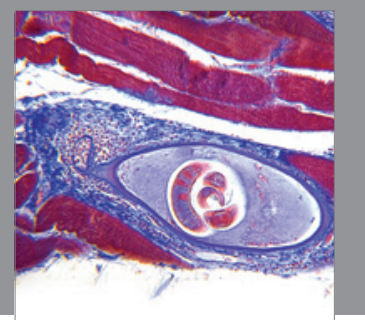

Gastroenterology

Research and Practice
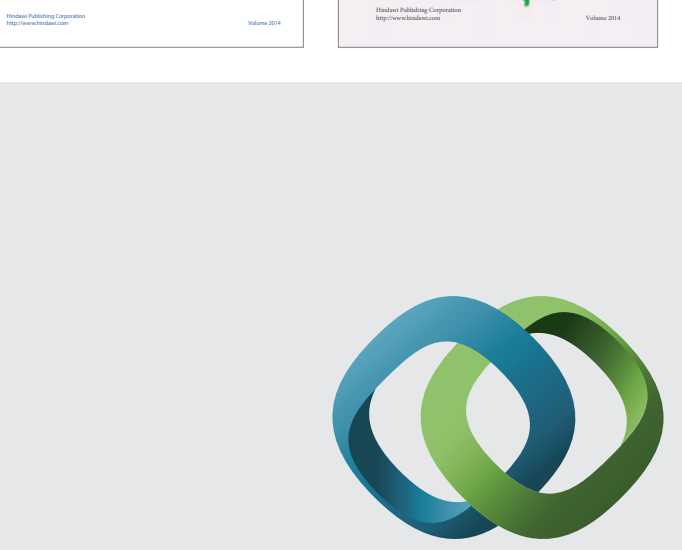

\section{Hindawi}

Submit your manuscripts at

http://www.hindawi.com
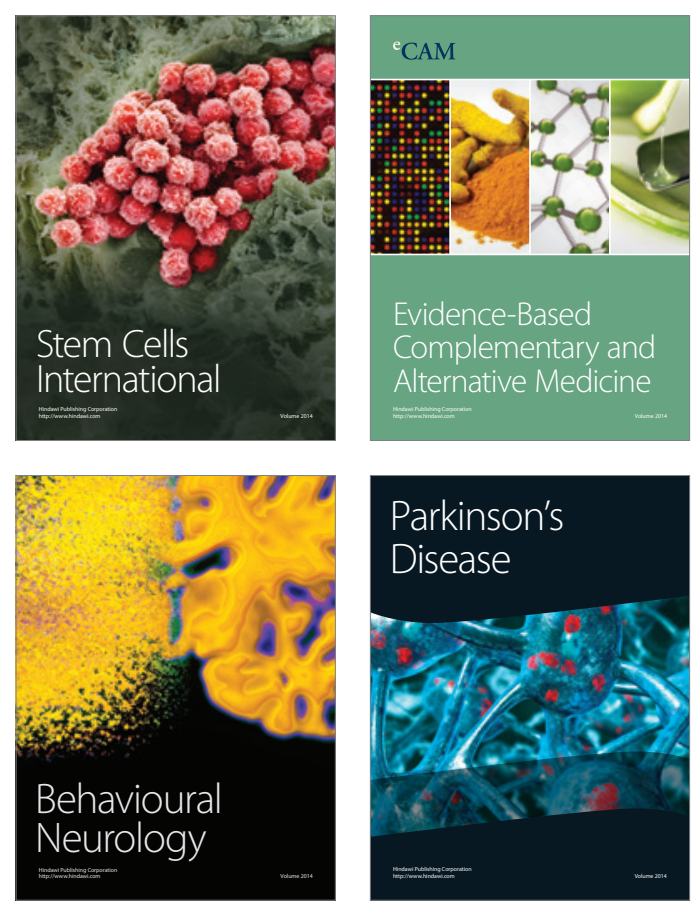

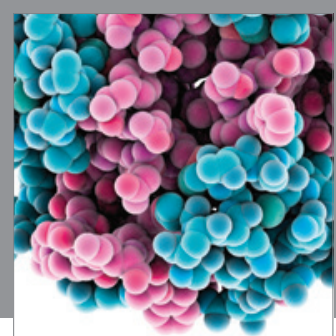

Journal of
Diabetes Research

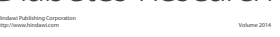

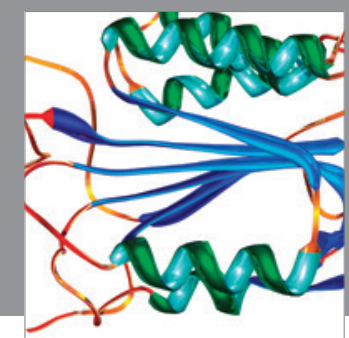

Disease Markers
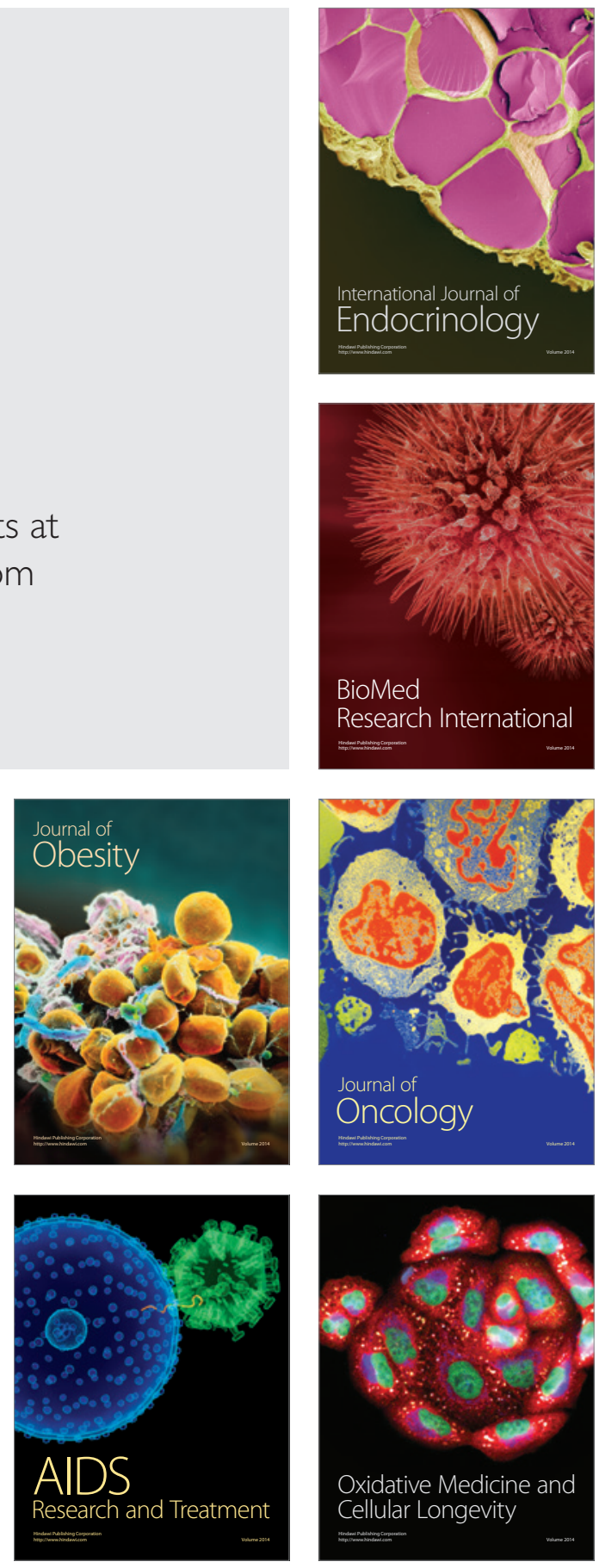